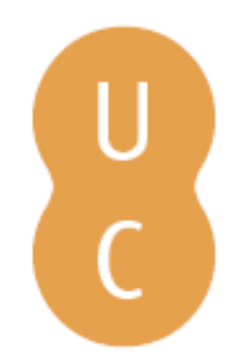

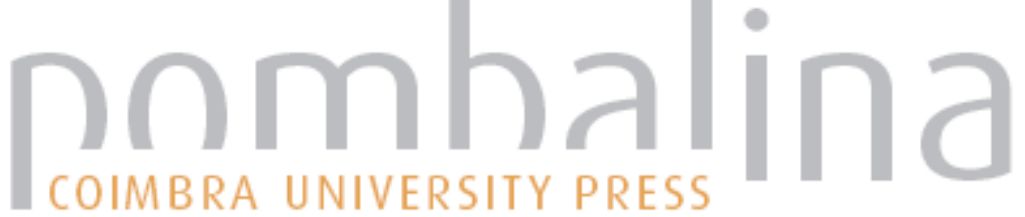

\section{Variação sazonal e espacial das propriedades físco-químicas da água do Rio} Caculuvar (Lubango, Angola)

\author{
Autor(es): $\quad$ Isaías, M.; Silva, M. M. V. G.; Gomes, E. M. C. \\ Publicado por: Imprensa da Universidade de Coimbra \\ URL \\ persistente: URI:http://hdl.handle.net/10316.2/31467 \\ DOI: $\quad$ DOI:http://dx.doi.org/10.14195/978-989-26-0534-0_37 \\ Accessed : $\quad$ 26-Apr-2023 13:54:55
}

A navegação consulta e descarregamento dos títulos inseridos nas Bibliotecas Digitais UC Digitalis, UC Pombalina e UC Impactum, pressupõem a aceitação plena e sem reservas dos Termos e Condições de Uso destas Bibliotecas Digitais, disponíveis em https://digitalis.uc.pt/pt-pt/termos.

Conforme exposto nos referidos Termos e Condições de Uso, o descarregamento de títulos de acesso restrito requer uma licença válida de autorização devendo o utilizador aceder ao(s) documento(s) a partir de um endereço de IP da instituição detentora da supramencionada licença.

Ao utilizador é apenas permitido o descarregamento para uso pessoal, pelo que o emprego do(s) título(s) descarregado(s) para outro fim, designadamente comercial, carece de autorização do respetivo autor ou editor da obra.

Na medida em que todas as obras da UC Digitalis se encontram protegidas pelo Código do Direito de Autor e Direitos Conexos e demais legislação aplicável, toda a cópia, parcial ou total, deste documento, nos casos em que é legalmente admitida, deverá conter ou fazer-se acompanhar por este aviso.

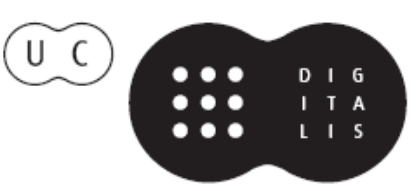





\title{
VARIAÇÁO SAZONAL E ESPACIAL DAS PROPRIEDADES FÍSIÇO-QUÍMICAS DA ÁGUA DO RIO CACULUVAR (LUBANGO, ANGOLA)
}

\author{
SEASONAL AND SPATIAL VARIATION OF \\ PHYSICO-CHEMICAL WATER PROPERTIES OF \\ THE RIVER CACULUVAR (LUBANGO, ANGOLA)
}

M. Isaías ${ }^{1}$, M. M. V. G. Silva² \& E. M. C. Gomes ${ }^{2}$

\begin{abstract}
Resumo - O Rio Caculuvar percorre a área urbana da cidade de Lubango, capital da província de Huila, no sudoeste de Angola. A cidade de Lubango tem crescido de forma anárquica, colocando as águas do rio sobre enorme pressão de origem antrópica. Este estudo tem como objetivos determinar as propriedades físico-químicas da água do rio Caculuvar e avaliar a influência das atividades antrópicas na variaçáo sazonal e espacial destas propriedades. Os parâmetros físico-químicos da água foram determinados em 13 pontos selecionados ao longo do rio, da nascente até à área urbana, e em três períodos distintos (setembro 2009 - época do cacimbo; novembro 2009 - início da época das chuvas; março 2010 - época das chuvas). Os resultados obtidos mostram variação sazonal da temperatura, $\mathrm{pH}, \mathrm{OD}, \mathrm{Eh}$, alcalinidade, fosfatos, nitratos, potássio e cobre. Observa-se, igualmente, uma variaçáo regular, ao longo do trecho estudado, dos parâmetros: $\mathrm{pH}$, condutividade elétrica, TSD, alcalinidade, amónia, nitratos, nitritos, fosfatos, cloro e potássio. Alguns parâmetros mostram que a qualidade da água do rio é influenciada por atividades de origem antrópica ao longo das margens, sendo a contaminaçáo mais evidente durante a época de pouca chuva e taxas de fluxo menores. Os menores valores de oxigénio dissolvido, os maiores valores de condutividade elétrica, superiores a $100 \mu \mathrm{S} / \mathrm{cm}$, e os maiores teores de fosfatos, acima do valor paramétrico indicado pela Legislação Portuguesa, foram observados nas águas amostradas na área urbana. Por outro lado, na época das chuvas, os teores de nitratos e cobre aumentam na água do rio devido à lixiviaçáo dos solos.
\end{abstract}

1 Escola do II Ciclo do Ensino Secundário da Arimba, Lubango, Angola; cotamala27@yahoo.com

2 Departamento de Ciências da Terra e Centro de Geociências, Faculdade de Ciências e Tecnologia da Universidade de Coimbra, 3000-272 Coimbra, Portugal; mmvsilva@dct.uc.pt; egomes@dct.uc.pt 
Palavras-chave - Rio Caculuvar; Água; Propriedades físico-químicas; Angola

Abstract - The River Caculuvar flows through the city of Lubango, the capital of the Huila province, southwest of Angola. This city has an extremely chaotic growth and human activities have placed enormous anthropogenic pressure on the waters of the river. This study was carried out to determine the physicochemical properties of the water of the River Caculuvar, and to assess the influence of human activities on the seasonal and spatial variation of these properties. The determination of physicochemical parameters of water was carried out in 13 selected points along the river, from near the source to the urban area, in three campaigns (September 2009-dry season; November 2009 - low rain; March 2010 - rainy season). The results show seasonal variation of the temperature, $p H$, dissolved oxygen, Eh, alkalinity, phosphates, nitrates, potassium, and copper. They also show a regular variation along the river of the $p H$, electric conductivity, TSD, alkalinity, ammonium, nitrates, nitrites, phosphates, chlorine, and potassium. Some parameters show that the river water quality is influenced by anthropogenic activities along its banks. This influence is greater during the low rainfall season when the flow rates are lower. The lowest dissolved oxygen values, the highest electrical conductivity of waters, above $100 \mu \mathrm{S} / \mathrm{cm}$, and the highest contents of phosphates, above the parametric value set out in the Portuguese Law, were found in the waters sampled in the urban area. On the other hand, during the rainy season, the nitrates and copper contents increase in the water due to leaching from soils.

Keywords - River Caculuvar; Water; Physico-chemical properties; Angola

\section{1 - Introduçáo}

Os cursos de água nos países em desenvolvimento estão sujeitos a fortes pressões antrópicas devido, fundamentalmente, a descargas de águas residuais e à atividade industrial e agrícola. Os corpos de água doce constituem a principal fonte disponível para abastecimento de água potável, por isso, a sua preservação e recuperação são essenciais para todos os que deles dependem.

O rio Caculuvar, afluente do rio Cunene, é o principal curso de água que percorre a cidade de Lubango, capital da província de Huíla, no sudoeste de Angola. O rio Caculuvar nasce na Serra da Chela, a cerca de $18 \mathrm{~km}$ a noroeste da cidade de Lubango. Tem um regime torrencial, com grandes caudais na época das chuvas, caracterizada por clima quente e húmido, de outubro a maio, e caudais reduzidos na época do cacimbo, com clima seco e temperaturas mais baixas, de maio a setembro. O rio corre sobre as rochas metassedimentares do Grupo da Chela (CARVALHO \& ALVES, 1993), principalmente quartzitos, na zona da nascente, e, em grande parte do seu percurso, para jusante, sobre granito biotítico de grão médio a grosseiro, que se enquadra no grupo dos Granitos Biotíticos da Região Central, datados do Paleoproterozóico (CARVALHO, 1980). No trecho da área urbana o rio corre em canal, erodindo depósitos de cobertura, atribuídos ao Plistocénico (MISSÃO PEDOLÓGICA DE ANGOLA, 1959), e desenvolvendo margens com taludes verticais, que podem atingir três metros de altura. Em todo o seu percurso, o leito é caracterizado por degraus que originam pequenos rápidos.

A cidade de Lubango tem uma população estimada de 1155898 habitantes. O abastecimento de água canalizada serve uma percentagem muito pequena da população, recorrendo 
esta a poços para se abastecer e ao rio para lavagem de roupa. A cidade tem crescido de forma anárquica, sem instrumento regulador e sem planeamento urbano. O êxodo rural tem promovido a proliferação dos bairros de barracas, os musseques, nos arredores da cidade. A ausência de infraestruturas sanitárias nestes bairros contribui para a degradação ambiental e, em especial, dos cursos de água.

Com este trabalho pretendeu-se determinar as propriedades físico-químicas da água do rio Caculuvar e avaliar a influência das atividades antrópicas na variaçáo sazonal e espacial destas propriedades.

\section{2 - Métodos}

Os parâmetros físico-químicos da água foram determinados em 13 pontos selecionados ao longo do rio, da nascente até à área urbana (Fig. 1), e em três períodos distintos. A primeira campanha foi realizada em setembro de 2009, na época do cacimbo, a segunda em novembro de 2009 , no começo da época das chuvas, e a terceira em março de 2010, em plena época das chuvas. Deve notar-se, contudo, que novembro de 2009 foi mais seco do que o normal, e que o mês de março de 2010 foi mais chuvoso e mais frio do que o normal. O fluxo do rio é quase sempre turbulento, com vários rápidos e pequenas cascatas, e varia ao longo do rio, que recebe contribuiçóes de tributários. O caudal é também muito variável, tanto ao longo do rio, como ao longo do ano.

As propriedades físicas e químicas da água de uma exsurgência localizada e que drena para o ponto 9 foram também determinadas, na segunda e terceira campanhas. No ponto 8 , muito próximo do ponto 7 , só se efetuaram registos na primeira campanha.

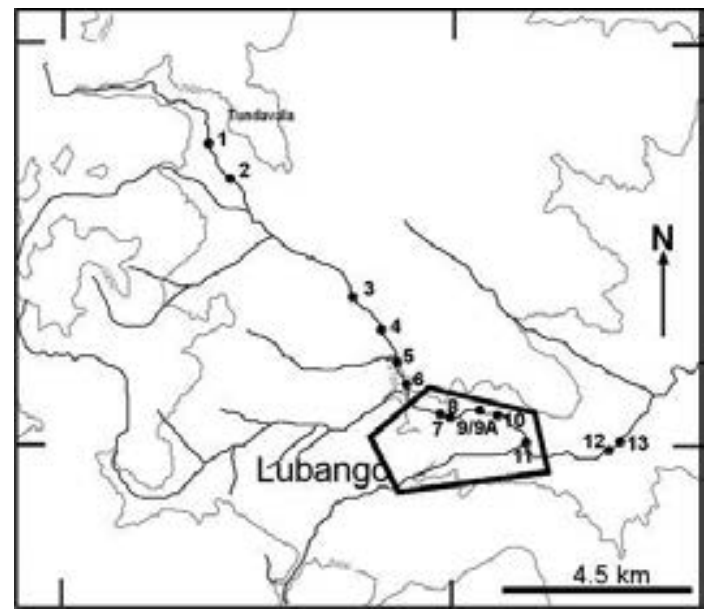

Fig. 1 - Localização dos pontos de amostragem ao longo do rio Caculuvar. Base topográfica: Carta de Angola, folha 335 (Sá da Bandeira-W) e 336 (Sá da Bandeira), à escala 1:100 000 (MISSÃO GEOGRÁFICA DE ANGOLA, 1957a, 1957b). Legenda: 1 - ponto mais a montante; 2 - antes da fábrica de refrigerantes; 3 - depois da fábrica de refrigerantes; 4 - campos agrícolas e pecuária; 5 e 6 - arredores da cidade; 7, 8 e 9 - área urbana; 9A - nascente que flui para o rio depois do ponto 9; 10 e 11 - área urbana; 12 e 13 - arredores da cidade. 
Em cada ponto selecionado determinaram-se os seguintes parâmetros físico-químicos da água: temperatura $\left({ }^{\circ} \mathrm{C}\right), \mathrm{pH}$, condutividade elétrica $(\mu \mathrm{S} / \mathrm{cm}), \mathrm{Eh}(\mathrm{mV})$, oxigénio dissolvido (OD em mg/L e \% de saturação) e o total de sólidos dissolvidos (TSD em mg/L). As determinaçóes foram realizadas com um medidor multiparâmetros portátil, da marca HANNA, modelo HI 9828, cuja precisáo é cerca de 10\%. Na segunda e terceira campanhas colheram-se amostras de água para a análise dos seguintes parâmetros químicos: alcalinidade, cloretos, fosfatos, sulfatos, nitratos, nitritos, potássio, magnésio, cobre e ferro. $\mathrm{Na}$ terceira campanha foram ainda determinadas as concentraçóes de amónia, zinco e crómio (VI). As análises químicas foram realizadas com um fotómetro de bancada, da marca HANNA, modelo HI 83200, com lâmpada de tungsténio e radiação UV-visível, que tem uma precisão de 4-10\%, seguindo o procedimento operacional da fotometria, e usando métodos colorimétrico e turbidimétricos.

\section{3 - Resultados e discussão}

Na figura 2a registam-se as variaçóes da temperatura da água do rio Caculuvar nas três campanhas. A temperatura média é mais elevada na campanha de novembro, variando de 20 a $24,8{ }^{\circ} \mathrm{C}$. No ponto $9 \mathrm{~A}$, não representado na figura $2 \mathrm{a}$, a temperatura da água subterrânea na campanha de novembro foi de $23,9{ }^{\circ} \mathrm{C}$, semelhante à da média das águas superficiais $\left(24^{\circ} \mathrm{C}\right)$. Na campanha de março a temperatura manteve-se constante, no valor de $23,9^{\circ} \mathrm{C}$, pois náo é influenciada pela variação da temperatura do ar, sendo mais elevada do que a média das águas superficiais $\left(21^{\circ} \mathrm{C}\right)$.

Os valores mais baixos do $\mathrm{pH}(5,5-6,4)$ foram registados em setembro, na época da seca, e os mais elevados (6,1-8,1), na época das chuvas intensas, em março. Os valores de $\mathrm{pH}$ medidos na época da seca são semelhantes ao das águas superficiais, em equilíbrio com a atmosfera (ANDREWS et al., 2004). Os valores mais elevados, determinados nas épocas de chuva, podem dever-se à lixiviação de contaminantes antropogénicos (nitratos, fosfatos e derivados de lixos) existentes nos solos, pois observou-se, em todas as campanhas, um aumento do $\mathrm{pH}$ da água do rio de montante para jusante (Fig. 2b), onde a influência humana é maior, indicando que a atividade humana contribui para o aumento do $\mathrm{pH}$ da água do rio.

Não se observou variação regular na variação dos teores de oxigénio dissolvido ao longo do rio, pois o rio possui vários rápidos que promovem oxigenação da água. Contudo, há um decréscimo geral nos teores de oxigénio dissolvido nos pontos localizados no interior da área urbana (Fig. 2c), onde a água atinge valores mínimos de zero mg/L. $\mathrm{Na}$ campanha de novembro, que corresponde ao começo da época das chuvas, os teores de oxigénio dissolvido são menores do que na campanha de março (chuvas intensas) (Fig. 2c), devido à menor oxigenação da água provocada pelo fluxo mais baixo. Quando o caudal do rio é menor, na campanha de novembro, os valores de oxigénio dissolvido, determinados na maioria dos pontos são inferiores ao valor paramétrico de $5 \mathrm{mg} / \mathrm{L}$ (Decreto-Lei 306/2007), da legislação Portuguesa. Na água subterrânea, os valores de $\mathrm{OD}$, determinados em novembro e março, são semelhantes, sendo 1,52 e 1,06 mg/L, respetivamente. 
Os valores de Eh variam entre $-55,7$ e $+177,8 \mathrm{mV}$ na campanha de novembro, e entre $-56,7 \mathrm{mV}$ a $71,5 \mathrm{mV}$ na campanha de março. Não se observou variação regular neste parâmetro ao longo do rio (Fig. 2d). Os valores de Eh negativos são reflexo da grande quantidade de matéria orgânica que a água do rio possui, o que lhe confere cheiro nauseabundo nalguns troços. Esta matéria orgânica é adicionada pelas descargas de efluentes domésticos que correm a céu aberto. $\mathrm{O}$ valor de Eh da água subterrânea foi constante nas duas campanhas $(-99,6 \mathrm{mV})$. Os padrốes de variação dos teores de oxigénio dissolvido e do Eh, encontrados na campanha de novembro, são semelhantes (Fig. 2e), indicando que os valores de Eh são controlados pela quantidade de oxigénio dissolvido, o que não se observou na campanha de chuvas intensas (março), pois as águas são muito mais arejadas.

Os valores da condutividade elétrica são semelhantes e variam entre 16 e $394 \mu \mathrm{S} / \mathrm{cm}$, nas duas campanhas onde este parâmetro foi analisado. Os valores de salinidade dos pontos 1 e 2, localizados mais a montante e onde a influência antrópica é reduzida, permitem classificar esta água do rio próximo da sua nascente como hipossalina (APIAM, 2001). Observa-se um aumento na condutividade elétrica da água do rio desde o ponto 1 até ao ponto 13 (Fig. 2f), com valores indicativos de ambientes impactados, ou seja $>100 \mu \mathrm{S} /$ cm (CETESB, 2001), na área urbana. Portanto, a influência humana na composição da água do rio é manifestada por um aumento na condutividade elétrica. A água subterrânea (ponto 9A) regista o maior valor de condutividade $(875 \mu \mathrm{S} / \mathrm{cm})$.

Foi observado um aumento da alcalinidade de montante para jusante $(5-70 \mathrm{mg} / \mathrm{L}$ $\mathrm{CaCO}_{3}$ ), na campanha de novembro, que não se observou na campanha de chuvas intensas (março). Na campanha de março (época chuvosa), a alcalinidade variou entre 5 e $20 \mathrm{mg} / \mathrm{L}$. O maior valor de alcalinidade $160 \mathrm{mg} / \mathrm{L}$ foi medido na água do ponto 9A, que corresponde a uma água subterrânea. Esta água é classificada como dura, de acordo com CUSTÓDIO \& LLAMAS (1983), pois possui valor de alcalinidade entre 100 e 200 mg/L de $\mathrm{CaCO}_{3}$.

No rio Caculuvar os teores de amónia medidos variaram entre 0,01 e 0,25 mg/L, sendo inferiores ao valor paramétrico indicador para as águas potáveis, segundo o DL 306/07, que é de 0,50 mg/L. Contudo, o Decreto-Lei 236/98, para águas doces superficiais destinadas à produção de água para consumo humano, indica como valor máximo admitido $0,05 \mathrm{mg} / \mathrm{L}$. O valor mais elevado $(0,25 \mathrm{mg} / \mathrm{L})$ foi medido no ponto mais a jusante. Os teores de nitrato medidos durante a época das chuvas intensas (março) variaram entre 4,2 e 11,2 mg/L, sendo superiores aos medidos na época mais seca (novembro), onde variavam entre 0,44 e $2,21 \mathrm{mg} / \mathrm{L}$. Isto pode dever-se ao facto da contaminação observada ser de origem difusa e provocada pelo arraste de compostos de nitrogénio (de fertilizantes nitrogenados), pelas águas de escorrência, nos solos usados para agricultura e pastoreio, e pelas águas pluviais, na zona urbana. Na campanha de novembro, os nitritos só foram detetados nas 4 amostras colhidas mais a jusante, atingindo $0,14 \mathrm{mg} / \mathrm{L}$. $\mathrm{Na}$ campanha de março os nitritos não foram detetados na maioria dos pontos de água amostrados, pois nesta época os teores de oxigénio dissolvido na água são superiores e terá ocorrido a sua oxidação rápida para nitratos. Todos os teores detetados de nitritos e nitratos são inferiores ao valor limite para águas para consumo humano (DL 306/07 da Lei Portuguesa). 

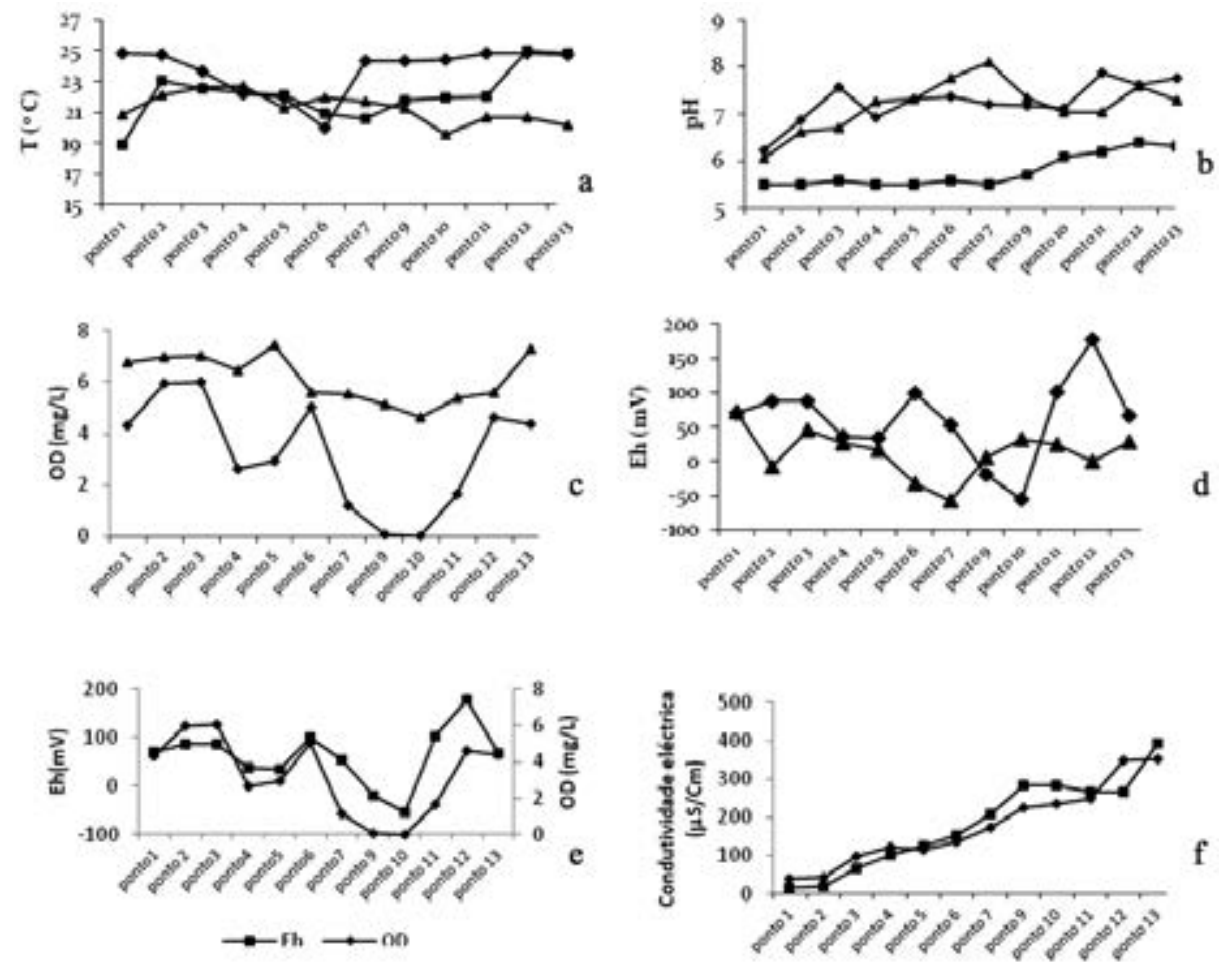

Fig. 2 - Variação de parâmetros físico-químicos da água do rio Caculuvar. Temperatura (a); pH (b); OD (c); Eh (d); Eh-OD na campanha de novembro (e); condutividade elétrica (f).

Legenda: quadrados - setembro 2009; losangos - novembro 2009; triângulos - março 2010.

Os teores de fosfato medidos decrescem com a diluição, pois os determinados na campanha de março, de chuvas intensas, são muito baixos e regulares, variando entre 0,03 e $0,45 \mathrm{mg} / \mathrm{L}$, enquanto na campanha de novembro, com pouca chuva e temperatura mais elevada, os teores de fosfato variaram entre 0,1 e $2 \mathrm{mg} / \mathrm{L}$ (Fig. 3a); ou seja, na época mais seca, em que a temperatura foi mais elevada e o rio possui menor caudal, observa-se um aumento nos teores de fosfatos na água do rio. Os teores mais elevados correspondem a locais onde há influência antrópica (Fig. 3a). Nesta figura observam-se mínimos nos pontos 5 e 6 , que correspondem a mínimos da temperatura.

Os teores de fosfatos na água do rio Caculuvar estão dependentes da influência antrópica, que faz aumentar os seus valores; do caudal do rio, que por efeito de diluição faz baixar os seus valores; e da temperatura, cujo aumento provoca um aumento da solubilidade do fosfato e consequente aumento dos teores. O DL 306/07 náo indica valor de referência para o fosfato para águas potáveis. Contudo, o DL 236/98 referente a águas doces superficiais destinadas à produção de água para consumo humano, indica como valor máximo recomendado 0,4 $\mathrm{mg} / \mathrm{L}$; portanto, de acordo com esta lei, as águas do rio Caculuvar na área urbana do Lubango náo deverão ser usadas para a produçáo de águas para consumo humano durante a época de mais calor e de menor caudal do rio. 
As concentrações de potássio nas águas no rio Caculuvar são superiores na campanha de novembro, de pouca chuva, e onde a temperatura da água era mais elevada (Fig. 3b). Na campanha de março deu-se o efeito de diluição, provocado pela maior quantidade de água do rio e menor temperatura, sendo as concentraçóes de K menores. Observa-se nas duas campanhas um aumento nos teores de K de montante para jusante (Fig. 3b).
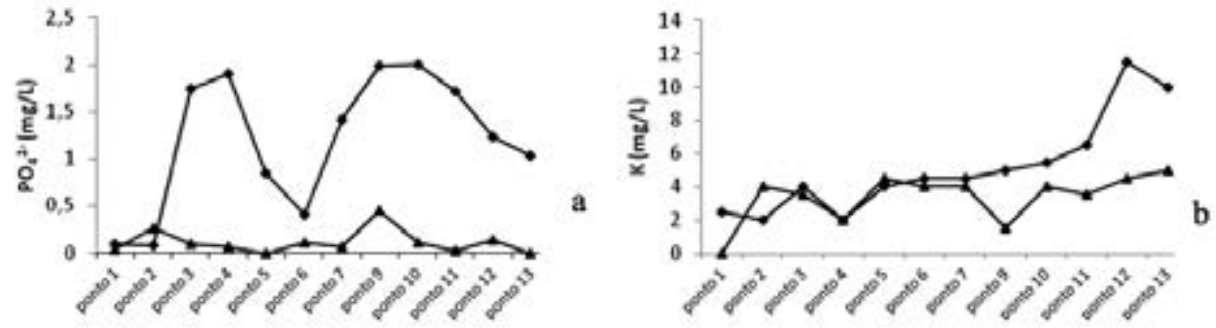

Fig. 3 - Variação dos teores de fosfato (a) e de potássio (b), da água do rio Caculuvar. Legenda: losangos - novembro 2009; triângulos - março 2010.

O crómio foi analisado apenas durante a campanha de março. Nas análises realizadas, este metal ocorre em concentraçóes variando entre $0 \mu \mathrm{g} / \mathrm{L}$ e $34 \mu \mathrm{g} / \mathrm{L}$, inferiores ao valor limite para águas de consumo humano, segundo o DL 306/07. Portanto as águas do rio Caculuvar não estão poluídas em $\mathrm{Cr}(\mathrm{VI})$. Contudo, deve observar-se que não foi detetado $\mathrm{Cr}(\mathrm{VI})$ na água do rio nos pontos localizados a montante da cidade (pontos 1 e 2), enquanto que a água do rio que recebe influência antrópica possui sempre $\mathrm{Cr}(\mathrm{VI})$, com exceção do ponto 7 , onde também não se detetou $\mathrm{Cr}(\mathrm{VI})$. Este facto pode ser devido ao baixo Eh que esta água possui $(-56,7 \mathrm{mV})$, que pode ter reduzido o $\mathrm{Cr}(\mathrm{VI})$.

As concentraçóes de zinco determinadas nas águas do rio Caculuvar variaram geralmente do não detetado a $0,05 \mathrm{mg} / \mathrm{L}$, apenas numa amostra atingiu $0,21 \mathrm{mg} / \mathrm{L}$, e são menores do que o valor máximo recomendado pelo Decreto-Lei $236 / 98$, que é de $0,5 \mathrm{mg} / \mathrm{L}$. Os teores de cobre determinados na água do rio Caculuvar durante a época de chuva mais intensa (março) variaram entre 23 a $123 \mu \mathrm{g} / \mathrm{L}$, enquanto na época de menos chuva o cobre raramente foi detetado nestas águas. Parece haver assim lixiviação de sais de cobre dos solos pelas águas de escorrência, para a água do rio. As concentrações de $\mathrm{Cu}$ nas águas amostradas foram sempre inferiores ao valor paramétrico de 2,0 mg/L (DL 306/2007), para as águas destinadas ao consumo humano.

As concentrações de Fe nas águas do rio não mostraram diferenças significativas entre as campanhas realizadas, sendo as médias de teores de 649 e $709 \mu \mathrm{g} / \mathrm{L}$, em novembro e março de 2010, respetivamente. Não se observou diferença entre os teores de ferro das amostras de água colhidas a montante e a jusante da cidade. Alguns dos teores determinados foram superiores ao valor paramétrico $(200 \mu \mathrm{g} / \mathrm{L})$ estabelecido para efeitos de controlo da qualidade da água destinada ao consumo humano (Decreto Lei 306/2007). Este limite é estabelecido em função de problemas estéticos relacionados com presença do ferro na água e do sabor que o ferro lhe confere. O ferro, ao oxidar, precipita sobre as louças sanitárias, azulejos e roupas, manchando-as. 


\section{4 - Conclusóes}

Os resultados obtidos mostram variação sazonal dos seguintes parâmetros: temperatura, $\mathrm{pH}, \mathrm{OD}$, alcalinidade, fosfatos, nitratos, potássio e cobre.

A temperatura é maior na época de menos chuvas (novembro). $\mathrm{O}$ pH e o oxigénio dissolvido são maiores na época de chuva intensa (março). Os maiores teores de oxigénio na época de chuvas intensas devem-se ao maior caudal e maior turbulência da água do rio. Os valores mais elevados de $\mathrm{pH}$ na época de chuvas mais intensas devem-se à lixiviação de contaminantes antrópicos.

A água apresenta frequentemente Eh negativos devido à grande quantidade de matéria orgânica que possui. Os valores de Eh são controlados pelos teores de oxigénio dissolvido na época de menos chuva. A alcalinidade tende a ser menor na época de chuvas intensas.

Os teores de nitratos e de cobre são maiores na época de chuvas mais intensas, devido à lixiviação dos solos agrícolas e aporte de águas pluviais com contaminantes antrópicos. Os teores de nitritos são menores na época de chuvas intensas, pois a oxigenação das águas é maior nesta época, o que promove a oxidação dos nitritos a nitratos.

Os teores de fosfato e potássio são menores na época de chuvas intensas devido ao efeito de diluição. Os teores de fosfato estão dependentes da temperatura e do caudal do rio.

Observa-se, igualmente, um aumento regular, ao longo do trecho estudado, desde a área situada mais a montante em direção à área urbana, dos parâmetros $\mathrm{pH}$, condutividade elétrica, alcalinidade, amónia, nitratos, nitritos, fosfatos, crómio(VI) e potássio e observa-se uma diminuição nos teores de oxigénio dissolvido.

Portanto, as águas do rio Caculuvar mostram-se impactadas pelas atividades antrópicas na regiáo de Lubango, sendo as contaminaçóes mais intensas durante a época em que o rio possui menor caudal. Por outro lado, durante a época mais chuvosa, os teores de nitratos e de cobre também aumentam na água do rio devido à lixiviação dos solos e aporte de águas pluviais.

A deterioração da qualidade da água é provocada, principalmente pelo descarte de esgoto doméstico, efluentes agrícolas e industriais e lixos a partir da cidade que, em alguns trechos, excedem a capacidade de autodepuração do rio, o que acarreta sensíveis alteraçóes nas condiçôes físico-químicas, possuindo a água do rio cheiro nauseabundo. Esta é a questáo de maior gravidade no quadro ambiental do rio em referência.

Agradecimentos - Agradecemos ao DCT pelo apoio.

\section{Referências Bibliográficas}

ANDREWS, J.E., BRIMBLECOMBE, P., JICKELLS, T.D., LISS, P.S. \& REID, B. (2004) - An Introduction to Environmental Chemistry, $2^{\text {sd }}$ edition. Blackwell Publishing, $182 \mathrm{pp}$.

APIAM (2001) - Cadernos APIAM, nº 3. Associação Portuguesa dos Industriais de Águas Minerais Naturais e de Nascentes, Lisboa.

CARVAlHO, H. (1980) - Geologia de Angola, Folha 3, à escala 1:1 000 000. Laboratório Nacional de Investigação Científica e Tropical. 
CARVAlHO, H. \& ALVES, P. (1993) - The Precambrian of SW Angola and NW Namibia. Comunicações do Instituto de Investigação Cientifica e Tropical, série de Ciências da Terra, 4, 38 p.

CETESB (2001) - COMPANHIA DE TECNOLOGIA DE SANEAMENTO AMBIENTAL. Relatório de estabelecimento de valores orientadores para solos e águas subterrâneas no Estado de São Paulo. http:// www.cestesb.sp.gov.br/solo/solo-geral.asp.

CUSTODIO, E. \& LLAMAS, M. R. (1983) - Hidrologia Subterrânea. 2a edición. Ediçôes Ómega, Barcelona. Tomo I, $1157 \mathrm{p}$.

DECRETO LEI no 236/98 de 1 de Agosto. Diário da República No 176 - 1-8-1998 - I Série-A. Ministério do Ambiente, Lisboa.

DECRETO-LEI N.o 306/2007 de 27 de Agosto. Diário da República, N.o 164/2007 - I série. Ministério do Ambiente, do Ordenamento do Território e do Desenvolvimento Regional. Lisboa.

MISSÃO PEDOLÓGICA DE ANGOLA (1959) - Carta geral dos solos de Angola. 1. Distrito da Huíla. Memórias da Junta de Investigação do Ultramar, 9, $421 \mathrm{p}$.

MISSÃO GEOGRÁFICA DE ANGOLA (1957a) - Carta de Angola. Levantamento aerofotogramétrico, folha 335 (Sá da Bandeira-W) Serviços Geográficos e Cadastrais, Governo Geral de Angola. 1.

MISSÃO GEOGRÁFICA DE ANGOLA (1957b) - Carta de Angola. Levantamento aerofotogramétrico, folha 336 (Sá da Bandeira) Serviços Geográficos e Cadastrais, Governo Geral de Angola. 1. 